\title{
Surgery for Congenital Heart Disease
}

\section{Extubation in the operating room after congenital heart surgery in children}

Alexander J. C. Mittnacht, MD, ${ }^{a}$ Maria Thanjan, MD, ${ }^{\mathrm{b}}$ Shubhika Srivastava, MD, ${ }^{\mathrm{b}}$ Umesh Joashi, MD, ${ }^{\mathrm{b}}$ Carol Bodian, PhD, ${ }^{a}$ Sabera Hossain, MS, ${ }^{a}$ Nobuhide Kin, MD, ${ }^{c}$ Ingrid Hollinger, MD, a and Khanh Nguyen, MD ${ }^{d}$

From the Department of Anesthesiology and Division of Pediatric Cardiology, ${ }^{\mathrm{b}}$ Mount Sinai Medical Center, New York, NY; Department of Anesthesiology, ${ }^{\mathrm{c}}$ University of Tokyo, Japan; and Department of Cardiothoracic Surgery, ${ }^{\mathrm{d}}$ Mount Sinai Medical Center, New York, NY.

Received for publication July 31, 2007; revisions received Nov 20, 2007; accepted for publication Nov 26, 2007.

Address for reprints: Alexander J. C. Mittnacht, MD, Mount Sinai Medical Center, One Gustave L. Levy Place, Box 1010, New York, NY 10029 (E-mail: alexander. mittnacht@msnyuhealth.org).

J Thorac Cardiovasc Surg 2008;136:88-93 0022-5223/\$34.00

Copyright $(\subset) 2008$ by The American Association for Thoracic Surgery

doi:10.1016/j.jtcvs.2007.11.042
Objective: Early extubation in the operating room after surgery for congenital heart disease has been described; however, postoperative mechanical ventilation in the intensive care unit remains common practice in many institutions.

The goal of this study was to identify perioperative factors associated with not proceeding with planned operating room extubation.

Methods: We performed a retrospective chart review of 224 patients (aged 1 month to 18 years, median 20 months) undergoing surgery for congenital heart defects requiring cardiopulmonary bypass. Patients mechanically ventilated preoperatively were excluded. A stepwise logistic regression model was used to test for the independent influence of various perioperative factors on extubation in the operating room.

Results: Overall, $79 \%$ of patients were extubated in the operating room. Younger age and longer cardiopulmonary bypass time were the strongest predictors for not extubating. Each step down to a younger age group $(<2,2-4,4-6,6-12,>12$ months) reduced the chance of extubation in the operating room by $56 \%$. Cardiopulmonary bypass time for more than 150 minutes was associated with an 11.8-fold increased risk of not being extubated.

Male gender and high inotrope requirement after cardiopulmonary bypass were also significantly associated with fewer children being extubated.

Conclusion: Extubation in the operating room after surgery for congenital heart disease was successful in the majority of patients. The strongest independent risk factors for failure of this strategy included younger age and longer cardiopulmonary bypass time.

$O$ urgery for congenital heart disease (CHD) using cardiopulmonary bypass (CPB) requires mechanical ventilation that in many cases is continued postoperatively in the intensive care unit (ICU). Institutional differences exist with respect to patient management. Certain centers attempt extubation in the operating room (OR), whereas others routinely continue mechanical ventilation postoperatively in the ICU.

Immediate extubation after CHD surgery was common practice in the early days of pediatric cardiac surgery. In 1980, Barash and colleagues ${ }^{1}$ published their experience with early extubation in 197 patients aged less than 3 years, including neonates; $61 \%$ were successfully extubated in the OR. More recently, several studies have shown that this practice can be performed safely. ${ }^{2,3}$ However, the definition of "early extubation" 


\section{Abbreviations and Acronyms \\ $\mathrm{CHD}=$ congenital heart disease \\ $\mathrm{CHF}=$ congestive heart failure \\ $\mathrm{CPB}=$ cardiopulmonary bypass \\ $\mathrm{ICU}=$ intensive care unit \\ $\mathrm{OR}=$ operating room \\ $\mathrm{PHT}=$ pulmonary hypertension}

has not been consistent, and studies have included children extubated within 24 hours of surgery. ${ }^{4}$ Furthermore, the success rate of tracheal extubation is variable and dependent on inclusion and exclusion criteria, such as patient age and case complexity.

After early encouraging results with extubation in the OR and excellent patient and parent satisfaction, we instituted a policy of attempting OR extubation in all patients undergoing CHD surgery who were aged more than 1 month and not mechanically ventilated preoperatively.

We provide a detailed analysis of perioperative factors that were present when extubation in the OR was not attempted. Determining independent predictive factors of successful extubation in the OR in a multiple regression analysis will assist practitioners in adopting an early extubation strategy in children after CHD surgery.

\section{Materials and Methods}

After institutional review board approval, we conducted a retrospective database review of pediatric patients undergoing surgery for CHD at The Mount Sinai Medical Center between July of 2002 and May of 2005. Patients included in this study were between 1 month and 18 years of age and underwent CHD surgery using CPB. Exclusion criteria were age less than 1 month, mechanical ventilation preoperatively, and thoracic organ transplantation. A total of 20 of 244 children were excluded from the final analysis because of significant inotrope use after separation from CPB (inotrope score $>15),{ }^{5}$ which we consider a contraindication for early extubation (see Table 1 for patients excluded). Overall, 224 patients were included in the final analysis.

Anesthesia was induced with sevoflurane in nitrous oxide/oxygen or intravenous ketamine and maintained with isoflurane in air/ oxygen. Preservative-free morphine was administered into the caudal space ( $<5$ years of age, $50-100 \mu \mathrm{g} / \mathrm{kg}$ ) or injected intrathecally ( $>5$ years of age, $5-10 \mu \mathrm{g} / \mathrm{kg}$ ). Fentanyl was intravenously administered as needed and limited to a cumulative dose of 3 to $5 \mu \mathrm{g} / \mathrm{kg}$ when extubation in the OR was planned. In hemodynamically unstable patients, intravenous ketamine (50-100 $\mu \mathrm{g} / \mathrm{kg} / \mathrm{min})$ was administered by continuous infusion. All patients had arterial blood pressure monitored continuously with an indwelling catheter and central venous access established before skin incision. A pediatric multiplane transesophageal echocardiography probe (Siemens Medical Solutions USA Inc, Malvern, Pa) was inserted for intraoperative hemodynamic monitoring and evaluating the surgical repair.
TABLE 1. Patients excluded from the final analysis because of high inotropic support following CPB

\begin{tabular}{rccl}
\hline $\mathbf{n}$ & Inotrope score & category & \multicolumn{1}{c}{ Lesion/repair } \\
\hline 1 & 26 & 3 & TOF \\
2 & 25 & 3 & VSD \\
3 & 20 & 1 & BT shunt \\
4 & 20 & 3 & TOF \\
5 & 19 & 4 & RV-PA conduit \\
6 & 21 & 1 & Bidirectional Glenn \\
7 & 20 & 3 & AVR \\
8 & 27.5 & 4 & Cor triatriatum \\
9 & 18 & 4 & Truncus arteriosus \\
10 & 30 & 4 & RV aneurysm \\
11 & 16 & 4 & ALCAPA \\
12 & 25 & 4 & Complete AV canal \\
13 & 22.5 & 3 & Partial AV canal \\
14 & 16 & 3 & VSD \\
15 & 40 & 3 & VSD \\
16 & 25 & 4 & Complete AV canal \\
17 & 17 & 4 & RV-PA conduit \\
18 & 35 & 4 & Complete AV canal \\
19 & 17 & 4 & Complete AV canal \\
20 & 27 & 4 & ALCAPA
\end{tabular}

$T O F$, Tetralogy of Fallot; $V S D$, ventricular septal defect; $B T$, Blalock-Taussig; $R V$ - $P A$, right ventricle to pulmonary artery; $A V R$, aortic valve replacement; $R V$, right ventricular; $A V$, atrioventricular; $A L C A P A$, anomalous origin of left coronary artery from pulmonary artery. Patients excluded from the final analysis because of high inotropic support (inotrope score $>15$ ) after CPB ( $n=$ number of patient, category $1=$ palliative simple, category $3=$ complete repair simple, category $4=$ complete repair complex).

After administration of heparin $300 \mathrm{U} / \mathrm{kg}$, the ascending aorta, inferior vena cava, and superior vena cava were cannulated and full CPB was established. At the end of the surgical procedure, after discontinuation of $\mathrm{CPB}$, modified ultrafiltration was performed in all patients. Heparin was reversed with protamine on the basis of a protamine-titration assay.

All patients included in this analysis were eligible for extubation in the OR on the basis of the above-mentioned criteria. However, the final decision to attempt extubation in the OR was made by the attending surgeon and anesthesiologist. At the end of the procedure, patients were considered for extubation if they were hemodynamically stable without excessive inotropic support, were normothermic, had no signs of upper airway edema, and showed no evidence of early surgical complications, such as bleeding requiring the administration of blood products. For the purpose of this analysis, inotrope use was quantified using a previously reported scoring system. ${ }^{5}$ Standard extubation criteria ${ }^{6}$ and satisfactory arterial blood gas results (appropriate for specific CHD lesion) were included in the decision process.

In patients in whom these criteria were met, residual neuromuscular blockade was reversed with neostigmine and glycopyrrolate. Once the patient was breathing spontaneously with adequate respiratory parameters, the endotracheal tube was removed and oxygen was administered via nasal cannulae. Morphine was intravenously administered to patients with signs of inadequate analgesia before transfer to the pediatric ICU. Patients in whom the attending 
anesthesiologist made the decision not to proceed with extubation were converted to a high-dose opioid technique and transferred to the ICU intubated.

\section{Statistical Methods}

Practice standard was to extubate all included patients in the OR. The primary outcome was defined as not proceeding with planned immediate OR extubation. Each potential perioperative risk factor was screened individually to determine any association with not proceeding, using the chi-square, Fisher exact, or Cochran-Armitage test for trend, as appropriate. If the $P$ value was less than .2, the variable was retained for further analysis in a stepwise logistic regression model, testing for the independent influence of the various perioperative factors on outcome. The following perioperative factors were tested: age; weight; weight percentile; gender; preoperative pulmonary hypertension (PHT), defined as pulmonary vascular resistance $>2$ Wood Units or systolic right-sided pressures greater than half systemic at preoperative cardiac catheterization or echocardiographic studies; congestive heart failure (CHF), as diagnosed by the attending pediatric cardiologist or the preoperative use of medications typically prescribed to relieve symptoms of $\mathrm{CHF}$ (diuretics, angiotensin-converting enzyme inhibitors, digoxin); trisomy 21; CPB time, aortic crossclamp time; procedure length; coagulopathy persisting after protamine administration; inotrope use, procedure type (palliative simple, palliative complex, complete

TABLE 2. List of cases/procedures performed, and the percentage of patients extubated in the operating room (OR)

\begin{tabular}{|c|c|}
\hline $\begin{array}{c}\text { Type/procedure } \\
\text { (No. of cases performed) }\end{array}$ & $\begin{array}{l}\text { Percentage of patients } \\
\text { extubated in } \mathrm{OR}\end{array}$ \\
\hline \multicolumn{2}{|l|}{ Palliative simple } \\
\hline Bidirectional Glenn $(n=17)$ & $65 \%$ \\
\hline Fontan $(n=29)$ & $97 \%$ \\
\hline \multicolumn{2}{|l|}{ Complete repair simple } \\
\hline $\operatorname{ASD}(n=34)$ & $91 \%$ \\
\hline $\operatorname{VSD}(n=54)$ & $76 \%$ \\
\hline $\operatorname{TOF}(\mathrm{n}=21)$ & $81 \%$ \\
\hline Subvalvular AS ( $\mathrm{n}=12$ ) & $92 \%$ \\
\hline Supravalvar AS $(n=4)$ & $75 \%$ \\
\hline \multicolumn{2}{|l|}{ Complete repair complex } \\
\hline Complete AV canal $(n=10)$ & $40 \%$ \\
\hline Partial AV canal $(n=5)$ & $60 \%$ \\
\hline RV-PA conduit $(n=11)$ & $100 \%$ \\
\hline MV/TV repair $(n=12)$ & $100 \%$ \\
\hline TAPVR $(n=4)$ & $50 \%$ \\
\hline $\operatorname{ALCAPA}(\mathrm{n}=4)$ & $25 \%$ \\
\hline Miscellaneous ( $\mathrm{n}=7$ ) & $43 \%$ \\
\hline Total $(n=224)$ & $79 \%$ \\
\hline \multicolumn{2}{|c|}{$\begin{array}{l}O R, \text { pperating room; } A S D \text {, atrial septal defect; } V S D \text {, ventricular septal } \\
\text { defect; TOF, tetralogy of Fallot; } A S \text {, aortic stenosis; } A V \text {, atrioventricular; } \\
R V-P A \text {, right ventricle to pulmonary artery; } M V / T V \text {, mitral valve to tricuspid } \\
\text { valve; TAPVR, total anomalous pulmonary venous return; } A L C A P A \text {, anoma- } \\
\text { lous origin of left coronary artery from pulmonary artery. List of cases/pro- } \\
\text { cedures performed and the percentage of patients extubated in the OR. } \\
\text { Palliative complex cases were all less than } 1 \text { month of age and thus not } \\
\text { included in this analysis. }\end{array}$} \\
\hline
\end{tabular}

repair simple, and complete repair complex); and previous open surgery (reoperation).

\section{Results}

Overall, $79 \%$ of patients (178/224) were extubated in the OR. Table 2 lists the type of cases and procedures performed and the percentage of patients extubated.

Multiple logistic regression revealed that younger age and longer CPB time were the strongest independent predictors for not proceeding with planned extubation in the OR. In addition, male gender and high inotrope use also were independently associated with an increased probability of mechanical ventilation on ICU admission. The analyzed factors, significance levels in the univariate analyses, and results of the multivariate analysis are presented in Table 3 and described in more depth below.

The median age of patients enrolled in this study was 20 months (range 1 month to 18 years). When the association of age with extubation was explored in the univariate analysis, it was evident that the risk of failing to extubate in the OR did not decline linearly with age, but rather decreased in a stepwise fashion, leveling off for patients aged more than 12 months. Subsequently, patients were divided into 5 age groups $(<2,2-4,4-6,6-12,>12$ months), coded 1 to

TABLE 3. Factors analyzed and associated odds ratios for not attempting immediate OR extubation

\begin{tabular}{|c|c|c|c|c|}
\hline \multirow[b]{2}{*}{ Factors } & \multirow{2}{*}{$\begin{array}{c}\text { Univariate analysis } \\
P \\
\text { value }\end{array}$} & \multicolumn{3}{|c|}{ Multivariate analysis } \\
\hline & & $\begin{array}{c}P \\
\text { value }\end{array}$ & $\begin{array}{l}\text { Odds } \\
\text { ratio }\end{array}$ & $\begin{array}{c}95 \% \\
\text { CI }\end{array}$ \\
\hline $\begin{array}{l}\text { Age group }(<2,2-4, \\
4-6,6-12,>12 \mathrm{mo})\end{array}$ & $<.0001$ & $<.0001$ & 0.44 & $0.31-0.64$ \\
\hline Weight & $<.0001$ & - & & \\
\hline Weight percentile & .015 & .16 & $\begin{array}{l}3.0 \ddagger \\
1.6 \S\end{array}$ & $\begin{array}{l}0.9-10.2 \ddagger \\
0.5-5.2 \S\end{array}$ \\
\hline Gender (male) & .04 & .03 & 2.6 & $1.08-6.27$ \\
\hline PHT & .0002 & - & & \\
\hline $\mathrm{CHF}$ & .0006 & - & & \\
\hline Trisomy 21 & .047 & - & & \\
\hline CPB time (>150 min) & $<.0001$ & $<.00011$ & 11.82 & $3.87-36.12$ \\
\hline $\begin{array}{l}\text { Aortic crossclamp } \\
\text { time }\end{array}$ & .0011 & - & & \\
\hline Procedure length & .0065 & - & & \\
\hline Coagulopathy & $<.0001$ & - & & \\
\hline Inotrope use & $<.0001$ & .03 & $\begin{array}{l}1.185^{*} \\
3.374 \dagger\end{array}$ & $\begin{array}{l}0.4-3.49^{*} \\
1.24-9.2 \dagger\end{array}$ \\
\hline Procedure type & .0037 & - & & \\
\hline $\begin{array}{l}\text { Experience of } \\
\text { anesthesiologist }\end{array}$ & .0029 & - & & \\
\hline
\end{tabular}

$\mathrm{Cl}$, confidence interval; $\mathrm{CHF}$, congestive heart failure; $C P B$, cardiopulmonary bypass; $P H T$, pulmonary hypertension. Factors analyzed and associated odds ratios for not attempting immediate $\mathrm{OR}$ extubation. * Inotrope score $5-9$ versus $<5$. †lnotrope score 10 to 15 versus $<5$. ‡Weight percentile $<5$ versus $\geq 40$. $\S$ Weight percentile $5-39$ versus $\geq 40$. 
5 , respectively in the multivariate analysis. Only $33 \%$ of patients in the group aged less than 2 months were extubated in the OR, compared with $92 \%$ of the patients aged more than 12 months. After controlling for the other factors in the multiple logistic regression model, the chance of extubation in the OR was estimated to decrease by 56\% $(P<.0001$, OR $=$ 0.44 ) for each step down to a younger age group.

$\mathrm{CPB}$ time was another independent factor associated with early extubation. Initial analyses failed to reveal a linear association; rather, failure to extubate in the OR remained low for CPB times less than 150 minutes $(28 / 192=15 \%)$ and increased markedly thereafter $(18 / 32=56 \%$ for CPB times $\geq 150$ minutes). Figure 1 shows the percentage of patients extubated in the OR in intervals of 30 minutes of CPB time. By multiple logistic regression, patients who underwent surgery with a CPB time $\geq 150$ minutes had an 11.8-fold increased risk of not being extubated in the OR compared with a CPB time $<150$ minutes. Aortic crossclamp time was not found to be an independent predictor of extubation in the OR.

Of the 224 patients, 121 were male. In the female group, 15 of 103 patients (14.56\%) were not extubated in the OR compared with 31 of 121 (25.62\%) of the male patients. In the multiple logistic regression model, the odds for male patients to not proceed with planned extubation in the OR was 2.6 times that for female patients $(P=.03)$.

Approximately half the patient population (49.6\%) had no inotropes or an inotrope score less than 5, 27.7\% of patients had scores between 5 and 9 , and $22.77 \%$ of patients had an inotrope score of 10 to 15 . We considered an inotrope score less than 5 to minimally influence the decision to extubate in the OR. Thus, in the multiple logistic regression model, high inotrope score (10-15) and moderate inotrope score (5-9) were each compared with the group with inotrope score less than 5 . The significance of inotrope use in the multivariate analysis $(P=.03)$ was due primarily to the increased risk of not extubating in the $\mathrm{OR}$ among patients with a high score $(\mathrm{OR}=3.74$ [CI 1.24-9.2]) compared with those with a score less than 5 .

The remaining factors associated with not extubating in the OR when considered in univariate analyses did not con-

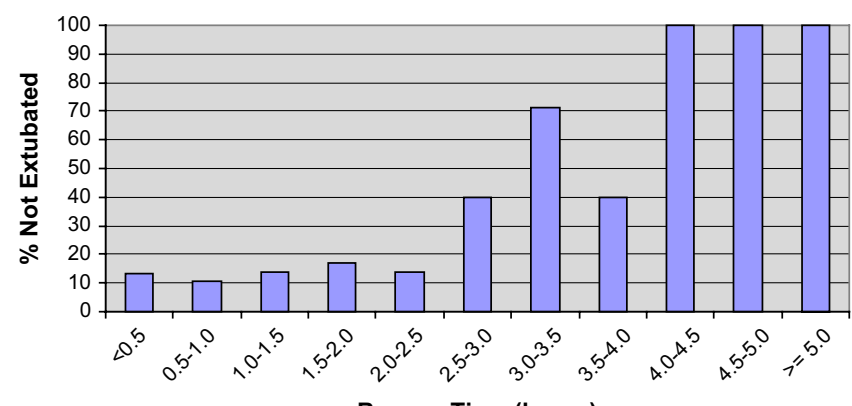

Bypass Time (hours)

Figure 1. Percentage of patients extubated in the $\mathrm{OR}$ in intervals of 30 minutes of CPB time. tribute significant independent information beyond that of the 4 factors described above. Fewer patients with preoperative PHT or CHF were extubated in the OR. However, neither PHT or CHF was independently associated with outcome.

Table 4 shows the probability of not proceeding with planned extubation in the OR with various combinations of factors and the $95 \%$ confidence intervals. Young male patients with longer CPB time and high inotrope score had the least probability of extubation.

None of the patients extubated at the end of the procedure required reintubation in the OR or at any time in the postoperative period in the ICU for respiratory-related complications, such as excessive respiratory depression, inadequate oxygenation, lung atelectasis, and so forth. Continuous positive airway pressure was applied via a nasal continuous positive airway pressure mask in selected infants with increased respiratory effort or poor aeration on the initial chest radiograph.

\section{Discussion}

Extubation in the OR after pediatric cardiac surgery is not common practice. After a favorable preliminary experience, we implemented an institutional policy to attempt extubation in the OR in all suitable patients. Patients less than 1 month of age were excluded. Consequently, all procedures performed in newborns, such as first-stage single-ventricle palliation, were excluded from the analysis. However, the list of procedures performed included complex lesions over a wide age range. Even though the surgeon and anesthesiologist at the end of the procedure made the final decision to extubate in the OR, all patients analyzed were candidates for early extubation based on our inclusion/exclusion criteria. The decision to not proceed with planned extubation is often based on multiple factors, and consequently it can be difficult to elucidate the exact reason(s) in a retrospective manner. However, factors found to independently predict failure of early extubation, such as long CPB time, interact with many of the criteria used to evaluate the potential for safe extubation (eg, myocardial function, hemostasis, airway edema).

Longer CPB time is consistently associated with prolonged mechanical ventilation after CHD surgery. ${ }^{1,7-10}$ This is not surprising, because longer $\mathrm{CPB}$ time is required for more complex cases or if unexpected difficulties occur. Despite this, the complexity of the cases alone did not predict successful extubation in the OR in our analysis. Furthermore, longer CPB time is associated with an increased risk of inflammatory response syndrome with generalized edema, decreased respiratory compliance, acute lung injury, and coagulopathy, all of which affect the ability to extubate a patient immediately after surgery.

Younger age is consistently associated with prolonged mechanical ventilation after CHD surgery. ${ }^{11,12}$ Often it is the preference of the anesthesiologist, surgeon, intensivists, or institutional policy not to extubate children after CHD surgery below a certain age. This is despite numerous 
TABLE 4. The probability of NOT extubating in the OR within various combinations of factors

\begin{tabular}{|c|c|c|c|c|c|c|c|c|c|c|}
\hline & \multicolumn{2}{|c|}{$<2 \mathrm{mo}$} & \multicolumn{2}{|c|}{ 2-4 mo } & \multicolumn{2}{|c|}{ 4-6 mo } & \multicolumn{2}{|c|}{ 6-12 mo } & \multicolumn{2}{|c|}{$\geq 12 \mathrm{mo}$} \\
\hline & $\mathbf{F}$ & M & $\mathbf{F}$ & $\mathbf{M}$ & $\mathbf{F}$ & $\mathbf{M}$ & $\mathbf{F}$ & M & $\mathbf{F}$ & M \\
\hline $\begin{array}{l}\text { CPB }<150 \text { min } \\
\text { Inotrope } \\
\quad \text { score }<5\end{array}$ & $\begin{array}{c}\mathbf{0 . 3} \\
(0.1-0.62)\end{array}$ & $\begin{array}{c}0.54 \\
(0.26-0.8)\end{array}$ & $\begin{array}{c}0.16 \\
(0.06-0.38)\end{array}$ & $\begin{array}{c}0.34 \\
(0.16-0.59)\end{array}$ & $\begin{array}{c}\mathbf{0 . 0 8} \\
(0.03-0.21)\end{array}$ & $\begin{array}{c}\mathbf{0 . 1 9} \\
(0.09-0.36)\end{array}$ & $\begin{array}{c}0.04 \\
(0.01-0.11)\end{array}$ & $\begin{array}{c}0.09 \\
(0.04-0.21)\end{array}$ & $\begin{array}{c}0.02 \\
(0.005-0.06)\end{array}$ & $\begin{array}{c}\mathbf{0 . 0 4} \\
(0.02-0.12)\end{array}$ \\
\hline $\begin{array}{l}\text { Inotrope score } \\
\qquad 5-9\end{array}$ & $\begin{array}{c}\mathbf{0 . 3 5} \\
(0.13)\end{array}$ & $\begin{array}{c}\mathbf{0 . 5 9} \\
(0.3-0.83)\end{array}$ & $\begin{array}{c}\mathbf{0 . 1 9} \\
(0.07-0.42)\end{array}$ & $\begin{array}{c}0.39 \\
(0.18-0.65)\end{array}$ & $\begin{array}{c}\mathbf{0 . 1 0} \\
(0.03-0.24)\end{array}$ & $\begin{array}{c}0.22 \\
(0.1-0.44)\end{array}$ & $\begin{array}{c}0.05 \\
(0.01-0.14)\end{array}$ & $\begin{array}{c}0.11 \\
(0.04-0.28)\end{array}$ & $\begin{array}{c}0.02 \\
(0.005-0.08)\end{array}$ & $\begin{array}{c}0.05 \\
(0.02-0.17)\end{array}$ \\
\hline $\begin{array}{l}\text { Inotrope score } \\
\quad 10-15\end{array}$ & $\begin{array}{c}0.56 \\
(0.28-0.8)\end{array}$ & $\begin{array}{c}0.77 \\
(0.52-0.91)\end{array}$ & $\begin{array}{c}0.36 \\
(0.16-0.62)\end{array}$ & $\begin{array}{c}0.60 \\
(0.36-0.8)\end{array}$ & $\begin{array}{c}0.20 \\
(0.08-0.42)\end{array}$ & $\begin{array}{c}0.40 \\
(0.2-0.64)\end{array}$ & $\begin{array}{c}\mathbf{0 . 1 0} \\
(0.03-0.27)\end{array}$ & $\begin{array}{c}0.23 \\
(0.09-0.47)\end{array}$ & $\begin{array}{c}0.05 \\
(0.01-0.17)\end{array}$ & $\begin{array}{c}0.12 \\
(0.04-0.33)\end{array}$ \\
\hline $\begin{array}{l}\text { CPB } \geq 150 \text { min } \\
\text { Inotrope score } \\
\quad<5\end{array}$ & $\begin{array}{c}0.83 \\
(0.47-0.97)\end{array}$ & $\begin{array}{c}0.93 \\
(0.68-0.99)\end{array}$ & $\begin{array}{c}\mathbf{0 . 6 9} \\
(0.31-0.92)\end{array}$ & $\begin{array}{c}0.86 \\
(0.55-0.97)\end{array}$ & $\begin{array}{c}0.50 \\
(0.19-0.81)\end{array}$ & $\begin{array}{c}\mathbf{0 . 7 3} \\
(0.39-0.92)\end{array}$ & $\begin{array}{c}\mathbf{0 . 3 1} \\
(0.1-0.64)\end{array}$ & $\begin{array}{c}0.55 \\
(0.24-0.82)\end{array}$ & $\begin{array}{c}0.17 \\
(0.05-0.44)\end{array}$ & $\begin{array}{c}\mathbf{0 . 3 5} \\
(0.13-0.67)\end{array}$ \\
\hline $\begin{array}{l}\text { Inotrope score } \\
\qquad 5-9\end{array}$ & $\begin{array}{c}0.86 \\
(0.55-0.97)\end{array}$ & $\begin{array}{c}0.94 \\
(0.76-0.99)\end{array}$ & $\begin{array}{c}0.74 \\
(0.4-0.92)\end{array}$ & $\begin{array}{c}\mathbf{0 . 8 8} \\
(0.63-0.97)\end{array}$ & $\begin{array}{c}0.55 \\
(0.26-0.82)\end{array}$ & $\begin{array}{c}0.77 \\
(0.47-0.92)\end{array}$ & $\begin{array}{c}\mathbf{0 . 3 6} \\
(0.14-0.65)\end{array}$ & $\begin{array}{c}\mathbf{0 . 6 0} \\
(0.3-0.84)\end{array}$ & $\begin{array}{c}0.20 \\
(0.06-0.47)\end{array}$ & $\begin{array}{c}\mathbf{0 . 4 0} \\
(0.15-0.71)\end{array}$ \\
\hline $\begin{array}{l}\text { Inotrope score } \\
10-15\end{array}$ & $\begin{array}{c}0.94 \\
(0.75-0.99)\end{array}$ & $\begin{array}{c}\mathbf{0 . 9 8} \\
(0.88-0.995)\end{array}$ & $\begin{array}{c}\mathbf{0 . 8 7} \\
(0.62-0.96)\end{array}$ & $\begin{array}{c}0.95 \\
(0.81-0.99)\end{array}$ & $\begin{array}{c}0.74 \\
(0.45-0.91)\end{array}$ & $\begin{array}{c}0.88 \\
(0.68-0.97)\end{array}$ & $\begin{array}{c}\mathbf{0 . 5 6} \\
(0.28-0.81)\end{array}$ & $\begin{array}{c}\mathbf{0 . 7 8} \\
(0.5-0.92)\end{array}$ & $\begin{array}{c}0.37 \\
(0.14-0.68)\end{array}$ & $\begin{array}{c}\mathbf{0 . 6 1} \\
(0.29-0.85)\end{array}$ \\
\hline
\end{tabular}

$C P B$, Cardiopulmonary bypass. The probability of NOT extubating in the $0 \mathrm{R}$ within various combinations of factors (calculated for 5-39 weight percentile). Bold numbers represent the proportion of patients NOT extubated within this combination of factors. Numbers in parentheses represent the $95 \%$ confidence interval for this combination of factors.

publications of successful early extubation strategies in all age groups, including neonates. ${ }^{13}$

Inotropic support after $\mathrm{CPB}$ is typically required in patients with compromised ventricular function. In our analysis, low levels of inotropic and vasoactive drugs did not prevent extubation in the OR. Increasing doses were an independent factor associated with not extubating in the OR. Obviously, patients who require high doses of inotropic support are usually too hemodynamically unstable to allow for safe early extubation.

An interesting finding of our analysis is that after adjusting for all other factors, including the complexity of the procedure, gender was an independent predictor of extubation in the OR. There are conflicting data in the literature on the impact of gender on outcome measures in patients with CHD. Although decreased survivals in male patients have been reported, ${ }^{14-16}$ increased mortality rates have been noted in female patients. ${ }^{17,18}$ The overall incidence of CHD is higher in female patients; ${ }^{19}$ however, more severe forms of CHD associated with increased mortality may be more prevalent in the male population. ${ }^{20}$ Therefore, it may be that female patients may undergo lower-risk surgical procedures compared with male patients. The underlying reason(s) why more male patients required postoperative mechanical ventilation in our population is not immediately obvious.

We also attempted to determine how the combination of 2 or more independent variables could predict the probability of extubation in our retrospective series. We found an additive effect of risk factors, with younger male patients with long CPB time and high inotropic support having the least likelihood of being extubated in the OR. This reflects our clinical experience, in which it is rarely only 1 factor that determines the decision to proceed or not to proceed with planned extubation in the OR, but rather the cumulative effect of several factors.

PHT and CHF, both generally accepted risk factors for adverse events (eg, prolonged mechanical ventilation) in children undergoing surgery for $\mathrm{CHD},{ }^{4,21}$ were not associated with extubation in the OR in our multiple regression model. However, in this analysis only data about preoperative PHT were available to us. PHT after CPB (eg, greater half systemic right-sided pressures) would be considered by most practitioners as a contraindication for an early extubation strategy.

Why should early extubation be attempted, in particular extubation in the OR? One may argue that there should not be a significant difference between extubation in the OR versus extubation shortly thereafter in the ICU. At our hospital (The Mount Sinai Medical Center, New York, New York), before the institution of an early extubation protocol, patient extubation after CHD surgery was determined by factors other than objective patient-focused parameters. They included nursing preferences, established practice, and preferences of individual ICU attendings, anesthesiologists, and surgeons. The majority of patients were sedated and not extubated until the following day. Consequently, discharge from the ICU (and hospital) was unnecessarily delayed.

Potential advantages of early extubation include 1) less airway irritation and ventilator-associated complications, 
such as accidental extubation, laryngotracheal trauma, pulmonary hypertensive crisis during endotracheal tube suctioning, mucous plugging of endotracheal tubes, barotrauma secondary to positive airway pressure ventilation, and ventilator-associated pulmonary infections and atelectasis; 2) reduced parental stress; 3 ) reduced requirements of sedatives (and associated hemodynamic compromise), ${ }^{22} 4$ ) more rapid patient mobilization; 5) earlier ICU discharge; 6) decreased length of hospital stay; and 7) reduced costs (ventilator-associated and length of ICU/hospital stay). Controlled mechanical ventilation is generally considered mandatory or beneficial in all patients who are hemodynamically unstable, coagulopathic patients, or patients who do not meet the above-mentioned extubation criteria.

In regard to cost-savings, it is difficult to compare one clinical setting with another. If a child is extubated within the first few hours after ICU admission (The Mount Sinai Medical Center, New York, New York), no real difference exists with respect to cost. ${ }^{23}$ However, at our institution, with the establishment of an early extubation policy, we reduced the ICU resource use and length of hospital stay, and thereby decreased overall costs.

The question remains: What is different today compared with 1979 when Glenn and colleagues ${ }^{24}$ and Barash and colleagues ${ }^{1}$ collected data on early extubation in children undergoing CHD surgery? It is our belief that extubating a child after CHD surgery is safer today compared with 28 years ago. Glenn and colleagues reported that $13 \%$ of patients who were extubated early required reintubation (14/18 cases for respiratory related reasons). ${ }^{24}$ In our series of 224 patients, none of the patients who were extubated in the OR required reintubation for respiratory distress or as a direct consequence of early endotracheal tube removal. We attribute this to improved surgical techniques, CPB refinements such as minimal priming volumes, the use of modified and conventional ultrafiltration techniques reducing the amount of lung water and edema, the availability of drugs with favorable pharmacokinetics (short plasma half-life), and fewer cardiorespiratory depressant anesthetic agents compared with drugs previously available.

\section{Conclusions}

Extubation in the OR after surgery for CHD was successful in the majority of patients (including infants) and after complex procedures. The strongest independent risk factors for failure to extubate included younger age and longer CPB time. Male gender and higher inotrope use were also significantly associated with fewer patients extubated in the OR. We conclude that extubation in the OR after CHD surgery can be performed safely.

Prospective randomized studies that address patient outcome in an early extubation versus a conservative model with mechanical ventilation continuing into the postoperative period are warranted.

\section{References}

1. Barash PG, Lescowich F, Katz JD, Talner NS, Stansel HC Jr. Early extubation following pediatric cardiothoracic operation: a viable alternative. Ann Thorac Surg. 1980;29:228-33.

2. Vricella LA, Dearani JA, Gundry SR, Razzouk AJ, Brauer SD, Bailey LL. Ultra fast track in elective congenital cardiac surgery. Ann Thorac Surg. 2000;69:865-71.

3. Kloth RL, Baum VC. Very early extubation in children after cardiac surgery. Crit Care Med. 2002;30:787-91.

4. Davis S, Worley S, Mee RBB, Harrison AM. Factors associated with early extubation after cardiac surgery in young children. Pediatr Crit Care Med. 2004;5:63-8.

5. Hoffman TM, Wernovsky G, Atz AM, Kulik TJ, Nelson DP, Chang AC, et al. Efficacy and safety of milrinone in preventing low cardiac output syndrome in infants and children after corrective surgery for congenital heart disease. Circulation. 2003;107:996-1002.

6. Aronson LA, Dent CL. Postoperative respiratory function and its management. In: Lake CL, Booker PD, eds. Pediatric Cardiac Anesthesia. 4th ed. Philadelphia: Lippincott-Williams \& Wilkins; 2005: 688-9.

7. Kanter RK, Bove EL, Tobin JR, Zimmermann JJ. Prolonged mechanical ventilation of infants after open heart surgery. Crit Care Med. 1986;14: 211-4.

8. Heard GG, Lamberti JJ Jr, Park SM, Waldman JD, Waldman J. Early extubation after surgical repair of congenital heart disease. Crit Care Med. 1985;13:830-2.

9. Peterson KL, DeCampli WM, Pike NA, Robbins RC, Reitz BA. A report of two hundred twenty cases of regional anesthesia in pediatric cardiac surgery. Anesth Analg. 2000;90:1014-9.

10. Schuller JL, Bovill JG, Nijveld A, Patrick MR, Marcelletti C. Early extubation of the trachea after open heart surgery for congenital heart disease. A review of 3 years' experience. Br J Anaesth. 1984;56:1101-8.

11. Bandla HPR, Hopkins RL, Beckerman RC, Gozal D. Pulmonary risk factors compromising postoperative recovery after surgical repair for congenital heart disease. Chest. 1999;116:740-7.

12. Neirotti RA, Jones D, Hackbarth R, Fosse GP. Early extubation in congenital heart surgery. Heart Lung Circ. 2002;11:157-61.

13. Heinle JS, Diaz LK, Fox LS. Early extubation after cardiac operations in neonates neonates and young infants. J Cardiovasc Surg. 1997;114:413-8.

14. Dearani JA, Danielson GK, Puga FJ, Schaff HV, Warnes CW, Driscoll DJ, et al. Late follow up of 1095 patients undergoing operation for complex congenital heart disease utilizing pulmonary ventricle to pulmonary artery conduits. Ann Thorac Surg. 2003;75:399-411.

15. Naeye RL, Burt IS, Wright DI, Blanc WA, Tatter D. Neonatal mortality, the male disadvantage. Pediatrics. 1971;48:902-6.

16. Wells JCK. Natural selection and sex differences in morbidity and mortality in early life. J Theor Biol. 2000;202:65-76.

17. Seifert HA, Howard DL, Silber JH, Jobes DR. Female gender increases the risk of death during hospitalization for pediatric cardiac surgery. J Thorac Cardiovasc Surg. 2007;133:668-75.

18. Chang RK, Chen AY, Klitzner TS. Female sex as a risk factor for inhospital mortality among children undergoing cardiac surgery. Circulation. 2002; 106:1514-22.

19. Marelli AJ, Mackie AS, Ionescu-Ittu R, Rahme E, Pilote L. Congenital heart disease in the general population. Changing prevalence and age distribution. Circulation. 2007;115:163-72.

20. Pradat P, Francannet C, Harris JA, Robert E. The epidemiology of cardiovascular defects, Part I: A study based on data from three large registries of congenital malformations. Pediatr Cardiol. 2003;14:195-221.

21. Harrison AM, Cox AC, Davis S, Piedmonte M, Drummond-Webb JJ, Mee RBB. Failed extubation after cardiac surgery in young children: prevalence, pathogenesis, and risk factors. Pediatr Crit Care Med. 2002;3:148-52.

22. Lofland GK. The enhancement of hemodynamic performance in Fontan circulation using pain free spontaneous ventilation. Eur J Cardiothorac Surg. 2001;20:114-8.

23. Laussen PC, Reid RW, Stene RA, Pare DS, Hickey PR, Jonas RA, et al. Tracheal extubation of children in the operating room after atrial septal defect repair as part of a clinical practice guideline. Anesth Analg. 1996; 82:988-93.

24. Glenn JD, Don HF, Ebert PA, Cohen NH, Matthay MA. Tracheal extubation after cardiac surgery in children. Anesthesiology. 1980;53:S158. 